\title{
Constraints Imposed by the Shape of Marine Magnetic Anomalies on the Magnetic Source
}

\author{
Steven C. Cande ${ }^{1}$ and Dennis V. Kent
}

Lamont-Doherty Geological Observatory of Columbia University, Palisades, New York 10964

\begin{abstract}
A two-layer source model for marine magnetic anomalies can accommodate several observations made on the shapes of anomalies in the Pacific and southeast Indian oceans. The layers are defined on the basis of cooling history and magnetic properties. The upper layer consists of rapidly cooled basalts, which acquire a strong magnetization near the ridge axis. This layer, with narrow transition zones, can account for the observed short polarity events. The lower layer consists of moderately magnetized, slowly cooled intrusive rocks in the lower oceanic crust. The transition zones in this layer are broad, sloping boundaries reflecting the delayed acquisition of magnetization with depth as, for example, along a sloping Curie point isotherm. The lower layer can account for a skewness discrepancy of $10^{\circ}-15^{\circ}$ in the observed skewness of some anomalies. It is shown that the upper layer has to contribute about three quarters of the total amplstude of magnetic anomalies in order for this model to simulate the observed shape of the anomalies. The model predicts that a deep drill hole located just to the older side of a reversal boundary in the upper part of the oceanic crust should encounter a magnetization polarity reversal within the lower oceanic crust.
\end{abstract}

\section{INTRODUCTION}

The shape of marine magnetic anomalies is dependent on the vertical and horizontal variations of magnetization within the oceanic crust. The simplest model for the source of marine magnetic anomalies assumes that they are caused by a layer of constant thickness and constant magnetization intensity separated into two-dimensional blocks of alternating polarity by narrow vertical transition zones. This model predicts that when marine magnetic anomalies are phase-shifted to the pole (i.e., the remanent magnetization and present magnetic field vectors are made vertical), they will appear to be symmetrical (in the skewness sense). However, recent studies indicate that there are systematic discrepancies between the observed skewness of some magnetic anomalies and the skewness predicted by the simple model. This conclusion is based on studies of anomalies 27-32 in the North and South Pacific [Cande, 1976] and anomalies 5-20 in the southeast Indian Ocean [Weissel and Hayes, 1972].

A skewness discrepancy is best seen in anomalies 27-32 in the Pacific. Cande [1976] analyzed the skewness of 35 magnetic profiles from six separate locations: two in the North Pacific, three in the southwest Pacific, and one in the southeast Pacific. The lineations in these locations were formed at a variety of azimuths and spreading rates. In each area a mean value of skewness $\theta$ and the half width $\Delta \theta$ of the $95 \%$ confidence interval were determined by averaging the skewnesses of several anomalies on each of several profiles. Although there is a range of skewnesses for individual anomalies, $\Delta \theta$ in all areas was of the order of $6^{\circ}$. As an example of a skewness discrepancy, in Figure 1 we show five profiles from the southwest Pacific south of the Eltanin (EL) fracture zone that have been phase-shifted to the Late Cretaceous paleomagnetic pole for the Pacific plate determined by Cande [1976]. It should be noted that although a few of these anomalies resemble the model profile constructed at the pole, the average anomaly more closely resembles the model profile constructed with a phase shift of $14^{\circ}$. In later figures we will use the EL33 profile as an example of the observed data, although it should be kept

${ }^{1}$ Also with Department of Geological Sciences, Columbia University, New York, New York 10027.

Copyright $(1976$ by the American Geophysical Union. in mind that we are attempting to model what we interpret as a systematic skewness discrepancy and not necessarily the skewness of any one anomaly on any individual profile.

The skewness discrepancy found for anomalies 27-32 in the Pacific is characterized by three observations [Cande, 1976]: (1) these anomalies appear to be skewed by about $10^{\circ}$ when they are phase-shifted to the pole (Figure 1), (2) the skewness of these anomalies on opposite sides of the Pacific-Antarctic ridge differs by approximately equal but opposite amounts, and (3) the magnitude of the skewness discrepancy appears to be spreading rate dependent $\left(10^{\circ}-15^{\circ}\right.$ for a spreading rate of $4.75 \mathrm{~cm} / \mathrm{yr}$ but only $5^{\circ}-10^{\circ}$ for a spreading rate of $3.5 \mathrm{~cm} / \mathrm{yr}$ ). Weissel and Hayes [1972], in a study of anomalies in the southeast Indian Ocean, observed that there was a total skewness discrepancy of approximately $20^{\circ}$ across the ridge crest in anomalies 5-20, although they did not observe a skewness discrepancy in anomalies younger than anomaly 5 .

Skewness discrepancies have only been found to date in a few areas. However, since it is often difficult to measure skewness accurately, skewness discrepancies could be present and unnoticed in other areas. For example, it is difficult to measure the skewness of anomalies when the reversal boundaries are closer together than about $20 \mathrm{~km}$. It should also be pointed out that there are areas in which skewness measurements have been made but no systematic skewness discrepancies were found, as, for example, in anomalies M1-M10 in the Pacific Ocean [Larson and Chase, 1972].

Two general ways of explaining the skewness discrepancy in anomalies 27-32 in the Pacific have been suggested [Cande, 1976]. The first is to modify the assumed behavior of the paleomagnetic field. For example, there may be an increasing number of undetected short polarity events toward the end of long intervals of predominantly one polarity. The second is to modify the nature of the source layer: either the average remanent magnetization vector may be rotated from its original direction, or the configuration of the transition zones between the blocks of alternating polarity may be modified. For the purposes of this paper it will be assumed that the paleomagnetic field does not contribute to the skewness discrepancy and also that the average direction of the remanent magnetization vector in the magnetic source is the same as the paleomagnetic field direction at the time at which the magnetization was 

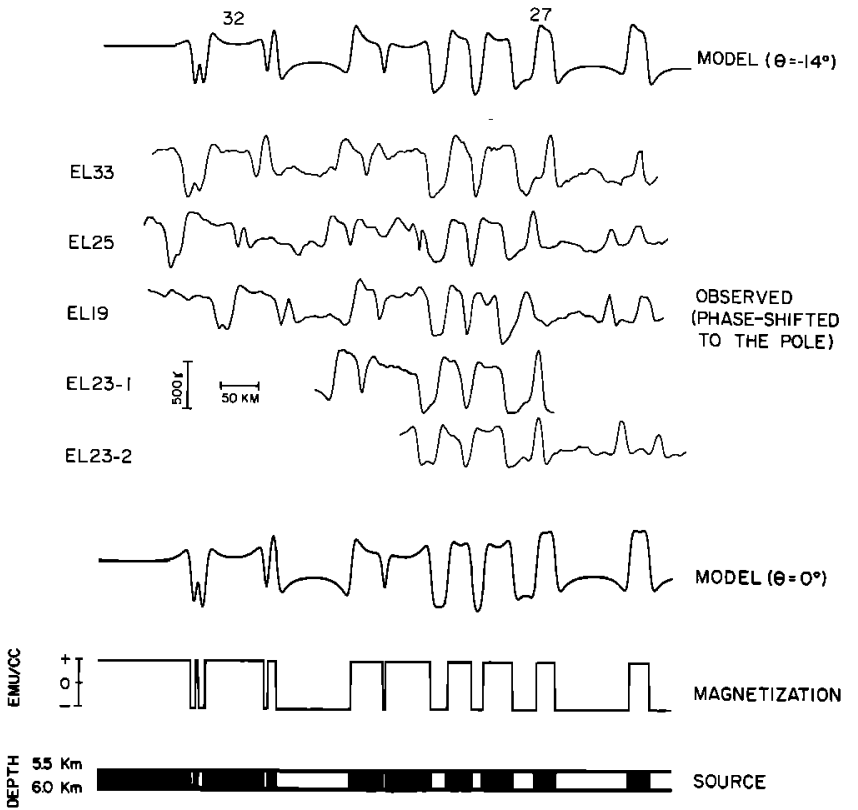

Fig. 1. Models generated at the pole $\left(\theta=0^{\circ}\right)$ and phase-shifted by $-14^{\circ}\left(\theta=-14^{\circ}\right)$ for a simple one-layer source, assuming blocks of constant magnetization but alternating polarity separated by narrow vertical transition zones for anomalies 27-32, compared to observed EL profiles from the southwest Pacific that have been phase-shifted to the Late Cretaceous pole of Cande [1976]. On the average, the observed profiles phase-shifted to the pole more closely resemble in shape the model profile phase-shifted by $-14^{\circ}$ than they do the model generated at the pole. This apparent phase shift in the observed profiles is referred to as a skewness discrepancy.

acquired. Making these assumptions, we will consider the effects of modifying the configuration of the transition zones to produce a skewness discrepancy.

\section{Asymmetrical Transition Zones}

The observation that some magnetic anomalies appear to be skewed by $10^{\circ}-15^{\circ}$ when they are phase-shifted to the pole suggests that the transition zones between the source blocks of alternating polarity may be asymmetrical. Schouten and McCamy [1972] and Atwater and Mudie [1973] previously noted that the effect of a nonvertical transition zone, such as can be produced, for example, by either their extrusion (flow) or intrusion (dike) model, is to introduce a phase shift in the magnetic anomalies. To investigate the effects of an asymmetrical transition zone, we followed the method developed by Schouten and McCamy [1972], who showed that magnetic anomalies can be modeled by using linear filtering techniques. We have chosen one of their filters, the half-Gaussian filter, to simulate the effect of an asymmetrical ridge crest process in the formation of the magnetic layer, such as by the ponding of extruded lavas. In a general sense, this filter simulates any process which leads to a transition zone in which the magnetization distribution has the shape of an integrated half-Gaussian curve. Such a magnetization distribution can also be viewed as a cross section through the magnetic layer, oppositely magnetized blocks being separated by a surface in the shape of an integrated half-Gaussian curve (see the appendix). The effects of this filter are to (1) smooth the anomaly pattern and (2) phase-shift the anomalies. The amount of smoothing and phase shifting is determined by the width of the filter. It is specified by the standard deviation $\sigma$ of the width of the transition zone.
Using the half-Gaussian filter to make preliminary models of the magnetic source, we reached the general conclusion that the skewness discrepancy could not be explained by modifying the shape of the transition zones of a simple one-layer model. This is a result of the fact that in order to generate a $10^{\circ}-15^{\circ}$ phase shift for the spreading rate of $5 \mathrm{~cm} / \mathrm{yr}$ assumed in all models in this paper, the standard deviation $\sigma$ of the halfGaussian filter has to be of the order of 10-20 km ( $\sigma$ has to be scaled appropriately for other spreading rates). The effects of this filter are twofold (Figure 2). First, the phase shift produced by a half-Gaussian filter is not uniform. Certain frequencies are phase-shifted more than others, a distortion in the magnetic anomaly profile thus being produced. This distortion is not apparent in the observed data. Second, the anomalies due to the short polarity intervals are lost owing to the smoothing effect of the broad half-Gaussian filter. However, such anomalies are apparent in the observed record, particularly the small positive anomaly between anomalies 32 and 33 which can be identified consistently in magnetic profiles worldwide.

The asymmetry of the half-Gaussian filter causes the phase shift, and asymmetric distributions other than half-Gaussian will have similar phase-shifting effects [Schouten and McCamy, 1972], not necessarily in the same sense. For example, the filter that can be used to simulate the dike injection process is also asymmetric but produces a phase shift in the opposite sense to that produced by a flow model [Atwater and Mudie, 1973] and to the observed skewness discrepancy. In any case our modeling studies suggest that a broad zone of dike injection or lava flows of the order of $15 \mathrm{~km}$ from the ridge crest would be required to produce $10^{\circ}-15^{\circ}$ of skewing; such a broad emplacement mechanism for a single-layer model of the magnetic source would result in smoothing and distortion incompatible with the magnetic profiles that we studied.

\section{Proposed Two-Layer Source}

We propose a two-layer magnetic source model that can explain the observed $10^{\circ}-15^{\circ}$ phase shift in magnetic anomalies. Although a two-layer source model has been proposed by others [e.g., Cox et al., 1972], our model accounts for a different set of observations and has different characteristics, as is discussed below. The layers are defined on the basis of cooling

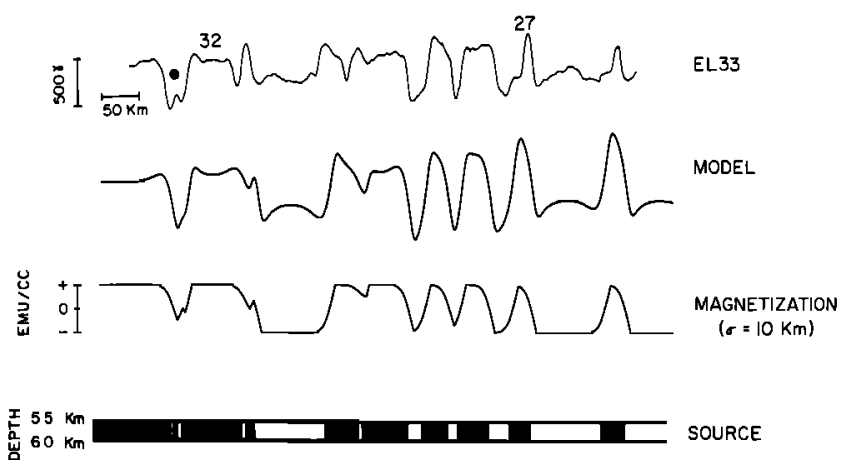

Fig. 2. Model generated at the pole for a simple one-layer source, assuming blocks of alternating polarity separated by broad slanting transition zones for anomalies 27-32, compared to the EL33 profile phase-shifted to the pole. The broad slanting transition zones were modeled with a half-Gaussian filter with a width $\sigma$ of $10 \mathrm{~km}$. Although the model profile does appear slightly phase-shifted, as does the observed profile, the effect of the broad slanting transition zones is to smear out anomalies due to short polarity intervals (e.g., the small anomaly near 32 , indicated by dot) and to distort the entire profile. 
history and magnetic properties. The upper layer consists of rapidly cooled basalts, generally assumed to be the dominant source of marine magnetic anomalies. It is assumed in our model that the magnetization of this layer is concentrated in the top $500 \mathrm{~m}$, as was suggested by Talwani et al. [1971], although our model would be equally valid if the upper layer was uniformly and more weakly magnetized or if the magnetization was concentrated elsewhere in this layer. The transition zones in this layer are narrow, of the order of 2 or $3 \mathrm{~km}$ wide for moderate spreading rate ridges. It is proposed that this layer contributes about three quarters of the total amplitude of magnetic anomalies.

The lower layer consists of moderately magnetized, slowly cooled intrusive rocks in the lower oceanic crust. The transition zones in this layer are broad, sloping boundaries reflecting the delayed acquisition of magnetization with depth along an isotherm. It is proposed that this layer contributes about one quarter of the total amplitude of magnetic anomalies.

A model of anomalies 27-32 for a two-layer source closely resembles the observed magnetic anomalies with an apparent $10^{\circ}-15^{\circ}$ phase shift (Figure 3 ). The upper strongly magnetized layer with narrow transition zones reproduces the known record of short polarity events. The transition zones in this layer probably reflect a combination of ridge crest processes such as the extrusion of lavas and dike injection and the finite period of time that it takes the field to reverse polarity. The lower layer with broad transition zones introduces a $10^{\circ}-15^{\circ}$ phase shift in the total magnetic anomaly profile. The transition zones in this layer are modeled by using the half-Gaussian filter (see the appendix). Unlike the single-layer model, there is little distortion introduced into the combined profile. The phase shift is fairly uniform for both long- and short-wavelength anomalies.

\section{Upper Layer}

The upper layer in our model consists of oceanic crustal rocks that have cooled rapidly and acquired a thermoremanent magnetization (TRM) near the ridge axis. The top of this layer corresponds to seismic layer 2A [Talwani et al., 1971], which apparently is composed of a pile of rapidly quenched pillow basalts [Fox et al., 1973] and is strongly magnetized, as has been calculated from the magnetization of basement topography [Talwani et al., 1971; Atwater and Mudie, 1973]. Magnetic measurements on dredged rocks [Fox and Opdyke. 1973], Deep-Sea Drilling Project (DSDP) basalts [Lowrie, 1974], and ophiolites [Moores and Vine, 1971; Vine and Moores, 1972; Butler and Banerjee, 1973] show that in addition to high magnetization intensities these basalts usually possess high Königsberger ratios and good magnetic stabilities, characteristics necessary for the production and preservation of marine magnetic anomalies. The studies by Vine and Moores [1972], Talwani et al. [1971], and Atwater and Mudie [1973] suggest that this magnetized layer needs to be of the order of only $0.5 \mathrm{~km}$ thick to produce marine magnetic anomalies. Material in this top layer is emplaced within a zone only 2 or 3 $\mathrm{km}$ wide on moderate spreading ridge crests [Atwater and Mudie, 1973].

Heat flow data [Williams et al., 1974; Anderson and Hobart, 1976] and petrologic studies of dredged rocks [Miyashiro et al., 1971; Bonatti et al., 1975] suggest that hydrothermal circulation may penetrate $2-3 \mathrm{~km}$ or more into the oceanic crust. Our upper layer would also include rocks that were cooled in this manner. Anderson et al. [1976] have suggested that hydrothermal circulation extends to the bottom of seismic layer $2 B$.
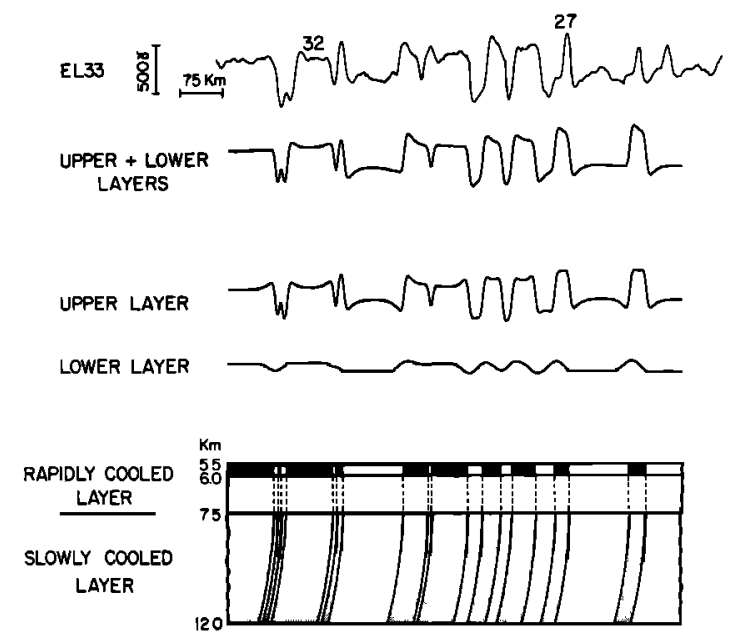

Fig. 3. Model generated at the pole for the proposed two-layer source, assuming blocks of alternating polarity for anomalies $27-32$, compared to the EL 33 profile phase-shifted to the pole. The upper layer has narrow vertical transition zones and contributes about three quarters of the total model amplitude. The lower layer has broad sloping transition zones, simulated by a half-Gaussian filter with a $\sigma=$ $15 \mathrm{~km}$, and contributes one quarter of the total model amplitude. This layer also introduces the $10^{\circ}-15^{\circ}$ phase shift similar to that present in the observed profiles (Figure 1). The magnetization in the upper layer has been assumed to be concentrated in the upper $500 \mathrm{~m}$, although it could just as well have been uniformly distributed. For this model the magnetization intensity of the upper layer is a factor of 10 greater than that of the lower layer.

The metabasalts of greenschist facies that may compose layer 2B [Fox et al., 1973; Peterson et al., 1974] are often weakly magnetized and have low Königsberger ratios and magnetic stabilities [Moores and Vine, 1971; Fox and Opdyke, 1973]. Therefore they would contribute very little to the amplitude of magnetic anomalies. We have modeled the lower part of our upper layer as a zone of zero magnetization, but as was mentioned earlier, this is not an essential feature of our model.

It is also possible that hydrothermal circulation penetrates into the top of layer 3. Although metagabbros, which may compose the upper part of layer 3 [Christensen and Salisbury, 1975], are more strongly magnetized than the overlying metabasalts [Fox and Opdyke, 1973], the effect of a moderately magnetized layer with narrow transition zones at this depth would simply be a further contribution to the anomaly amplitude from the rapidly cooled layer.

\section{Lower Layer}

The lower layer in our model consists of intrusive rocks that cool by conduction. The top of this layer corresponds to the deepest level of penetration of the hydrothermal convecting cells near the ridge axis. As was mentioned in the previous section, this level is a matter of speculation. Anderson et al. [1976] would place the level at the boundary between layers 2 and 3, although others would place it deeper [e.g., Lister, 1972]. For the purposes of our model we will assume a nominal $4.5-\mathrm{km}$-thick lower layer that correlates with all or a significant portion of seismic layer 3 [Christensen and Salisbury, 1975].

Several petrologic models for the composition of layer 3 have been proposed. On the basis of interpretations of seismic refraction data and compressive wave velocities of dredged rocks [Christensen and Salisbury, 1975; Fox et al., 1973] and the layering [Vine and Moores, 1972] and compressive wave 
velocities [Peterson et al., 1974] in ophiolites, layer 3 may be composed predominantly of unalterëd gabbro, although metagabbro [Christensen and Salisbury, 1975] or metadolerite [Peterson et al., 1974] may occur in the upper part of the layer. The analysis of dredged rocks [Fox and Opdyke, 1973] and ophiolites [Vine and Moores, 1972; Moores and Vine, 1971; Butler and Banerjee, 1973] suggets that the rocks likely to constitute seismic layer 3 (metagabbros and gabbros) possess moderate natural remanent magnetization (NRM) intensities and Königsberger ratios and have high magnetic stabilities. The NRM intensities of metagabbros and gabbros are of the order of $10^{-3} \mathrm{emu} / \mathrm{cm}^{3}$, or about 1 order of magnitude lower than the magnetization intensity of unmetamorphosed basalts. The limited amount of magnetic mineralogic data on ophiolite gabbros suggests that magnetite (Curie temperature of $580^{\circ} \mathrm{C}$ ) is the carrier of remanent magnetization [Butler and Banerjee, 1973].

Our model assumes that the acquisition of magnetization in the lower layer is directly related to the thermal structure, particularly to the position of the Curie point isotherm. Since the lower layer cools by conduction on moving away from the ridge axis, the Curie point isotherms will be in the form of broad sloping boundaries across which geomagnetic field reversals will be recorded. The width of the transition zone refers to the horizontal distance over which the sloping boundary occurs. A simple cooling model for this layer (see the appendix) shows that rocks at $4.5-\mathrm{km}$ depths within this layer would not cool to near $580^{\circ} \mathrm{C}$, the Curie point of magnetite, until $500,000 \mathrm{yr}(25 \mathrm{~km}$ at $5 \mathrm{~cm} / \mathrm{yr})$ after their emplacement near the ridge axis. The transition zone width in this case is of the order of $25 \mathrm{~km}$ and is modeled by a half-Gaussian filter with a $\sigma$ of about $15 \mathrm{~km}$. In reality, a thermoremanent magnetization would not be 'frozen in' until a rock had cooled through a range of blocking temperatures; however, they are generally concentrated a few tens of degrees below the Curie temperature. Although the horizontal distance over which the sloping boundary occurs is broad, the vertical separation between material of opposite magnetization polarity should be narrow, of the order of $0.5 \mathrm{~km}$, and simply reflects the separation between Curie point and effective blocking temperature isotherms at the time at which the geomagnetic field reverșed polarity.

\section{TEST OF MODEL}

The effect of our two-layer model is a function of the relative contributions of the upper and lower layers to the anomaly amplitude and the width $\sigma$ of the transition zone in the lower layer. We computed a series of models with different values of these parameters to (1) determine the range of values that resulted in model anomaly profiles most like those observed and (2) show that these optimum values were compatible with the known geophysical parameters of the oceanic crust. It was found (Figure 4) that the only models which were acceptable were those in which the top layer contributed more to the anomaly amplitude than the bottom layer. In general, the best models were for a top layer with approximately 3 times the amplitude contribution of the lower layer. For models with the amplitude contribution of the top layer significantly more than 3 times that of the lower layer, the lower layer could not introduce the necessary skewing effect. This appeared to be the case for any value of $\sigma$ for the lower layer. For models with the amplitude contribution of the top layer much less than 3 times that of the lower layer, the effect of the lower layer was to distort the anomaly profile and to smooth out the small-scale anomalies. This appeared to be the case for any reasonable value of $\sigma$ (i.e., $10-30 \mathrm{~km}$ ). It should also be noted that the limit to the amount of phase shifting that can be produced in our two-layer model without introducing distortion is about $30^{\circ}$. The distortion cbnsists of unequal amounts of phase shifting in the short- and long-wavelength anomalies and transition zones that appear broader than is observed.

The relative amplitude contributions depend primarily upon the depths, thicknesses, and magnetizations of the upper and lower layers. If we assume a magnetization of $0.007 \mathrm{emu} / \mathrm{cm}^{\mathrm{s}}$ and a thickness of $0.5 \mathrm{~km}$ [Talwani et al., 1971] for the upper layer and a magnetization of the order of $0.001 \mathrm{emu} / \mathrm{cm}^{\mathrm{a}}[$ [Fox and Opdyke, 1973] for the bottom layer, satisfactory model profiles are obtained for a bottom layer from 3 to $5 \mathrm{~km}$ thick. This thickness is compatible with the bottom layer's being all or a large part of seismic layer 3 [Christensen and Salisbury, 1975]. For these layer characteristics, values of $\sigma$ in the bottom layer have to be $10-30 \mathrm{~km}$ in order to introduce a $10^{\circ}-15^{\circ}$ phase shift. The half-Gaussian curves for these values of $\sigma$ (and these bottom layer thicknesses) approximate isotherms in the range of $500^{\circ}-600^{\circ} \mathrm{C}$. This is compatible with the hypothesis that the boundary is closely related to the magnetite Curie point isotherm in the lower layer.

We wish to emphasize that at this stage we do not seek to account for the amplitudes of any observed anomalies, only their skewness. This is because we can model the shapes in a general fashion (i.e., in terms of relative amplitude contributions) without specifying the exact magnetizations, depths, and thicknesses of these source layers. However, we can state that since our model requires that the top layer contribute only abqut three quarters of the anomaly amplitudes, either the magnetization or the layer thickness generally determined for the upper part of the oceanic crust for the single-layer concept to account for the anomaly amplitudes need not be as great with our two-layer model.

\section{Discussion}

The amplitudes of marine magnetic anomalies decrease rapidly within the first few million years, a phenomenon attributed to the progressive weathering of the pillow basalts [Irving, 1970; Marshall and Cox, 1972]. Our model predicts that the amount of skewness discrepancy (phase shift) should increase over this period of time as the upper layer contributes less and less to the total magnetization. Since the amount of the phase shift produced by the lower layer is a function of the relative contributions of the upper and lower layers, the phase shift would be a minimum near the ridge crest, where the top layer is most strongly magnetized, and would increase as the contribution from the top layer diminishes in amplitude.

Nevertheless, our model predicts that the contribution from the top layer continues to dominate that from the lower layer, even in older anomalies (e.g., anomalies 27-32). This is in contrast to the two-layer model of Cox et al. [1972] and Blakely [1976], in which the magnetization intensities of a top layer and a lower layer become approximately the same over a period of $60 \mathrm{~m} . y$. in order to explain an apparent increase in the width of the transition zone. The apparent width of the transition zone does appear to be slightly larger for anomalies 10 m.y. old [Cande and LaBrecque, 1974; Blakely, 1974] than for those near the ridge axis [Alwater and Mudie, 1973], but it does not appear to increase significantly for still older anomalies [Larson et al., 1975]. We interpret the relatively constant amplitude envelope of marine magnetic anomalies older than a few million years as the result of no further significant reduc- 
tion in the magnetization of the upper layer. Therefore we would not expect any significant increase in either skewness discrepancy or the apparent width of the transition zone after this time.

This model is compatible with the observation that the magnitude of the skewness discrepancy, which is related to both the depth and thickness of the slowly cooled lower layer and the position of the isotherms in that layer, appears to be spreading rate dependent. For example, R. N. Anderson (personal communication, 1976) has suggested that hydrothermal circulation penetrates deeper into the crust at slower spreading rates. Since this would amount to thinning our lower (conductively cooled) layer and moving it deeper, the phase-shifting effect would be reduced. In addition, although the position of the isotherms is assumed to be spreading rate independent in our simple model (Figure 5), it is spreading rate dependent in more complex models [Sleep, 1975; Parker and Oldenburg. 1973]. Skewness measurements in anomalies $27-32$ in the Pacific Ocean indicate that the amount of phase shifting is less for these anomalies formed at slower spreading rates. This might be explained by the deepening of the isotherms near the ridge crest at slower spreading rates as calculated by Sleep [1975] or as the result of deeper hydrothermal circulation.

This model also could accommodate petrologic models of the oceanic crust other than the one assumed here, although it is difficult to envision a controlling parameter other than conductive-cooling isotherms to explain satisfactorily the broad slanting magnetic boundaries in the lower layer. For example, partially serpentinized peridotites dredged from the ocean floor [Fox and Opdyke, 1973] and present in some ophiolites [Vine and Moores, 1972] often have high NRM intensities and Königsberger ratios, comparable with those obtained for pillow lavas. Serpentinized peridotite is not considered the domimant component but could constitute up to about $10 \%$ of layer 3 [Christensen, 1972]. The NRM of serpentinized peridotite is usually a chemical remanence acquired during serpentinization as a result of the formation of magnetite. Since serpentinization cannot occur above a temperature of about $500^{\circ} \mathrm{C}$, geomagnetic field reversals again could be recorded across broad slanting boundaries as the layer cools conductively through a 'serpentinization' isotherm [Vine and Moores, 1972]. On the other hand, a petrologic model involving intermittent off-axis accretion over a period of tens of millions of years of gabbros to the bottom of layer 3 [Christensen and Salisbury, 1975] is difficult to accornmodate unless perhaps an initial upper part of layer 3 is somewhat more highly magnetic and/or of greater thickness than is assumed here. Deep crustal drilling, as envisioned in the International Program of Ocean Drilling, could provide the necessary data, including the petrologic and magnetic properties and the extent of hydrothermal circulation with depth in the oceanic crust, to test the feasibility of the proposed two-layer magnetic source model. A rather deep hole drilled just to the older side of a reversal boundary in the upper oceanic crust in an area where a skewness discrepancy has been observed should encounter a magnetization polarity reversal in the lower oceanic crust if this model is correct.

\section{APPENDIX}

Theoretical isotherms within the lower layer are calculated from basic heat flow theory for cooling within a uniform semiinfinite conducting solid. The body is initially at a uniform temperature, and the top surface is kept at a constant temperature. By means of the assumption that there is negligible

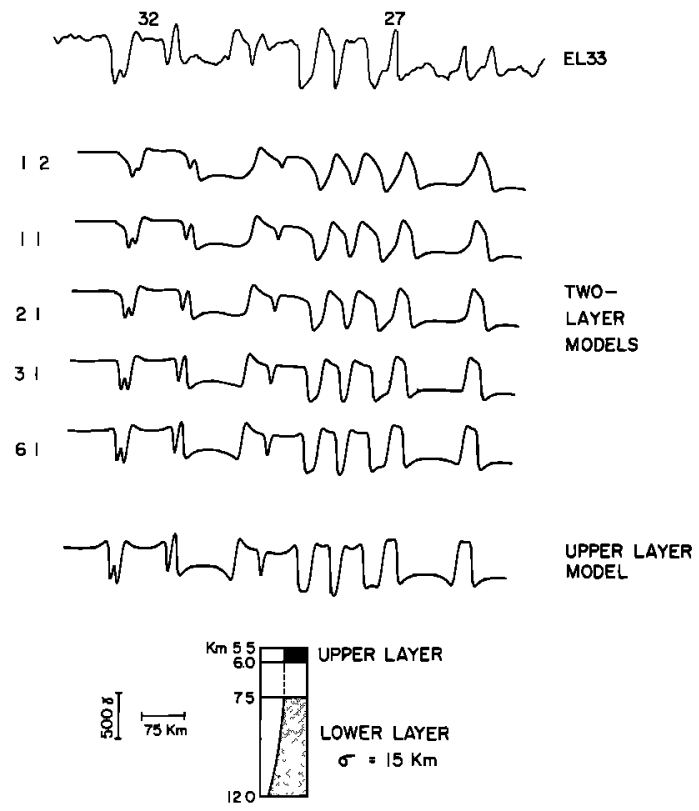

Fig. 4. Two-layer model profiles generated by varying the relative amplitude contributions (ratios at left of profiles) of the upper and lower layers compared to (1) the EL33 profile phase-shifted to the pole and (2) a model profile generated for the upper layer only. Models with relative contribution ratios near $3: 1$ best approximate the observed profile. All model profiles are generated at the pole.

horizontal heat transport, time is equivalent to horizontal distance from the ridge crest. The linear equation for heat flow under these conditions is

$$
\left(\partial^{2} T / \partial z^{2}\right)-k^{-1} \partial T / \partial t=0
$$

where $T$ is temperature, $z$ is the depth in the solid, $k$ is diffusivity, and $t$ is time.

For our case, we want the solution to the problem of the solid originally at the melting temperature $T_{m}$ and the top surface $z=0$ at constant zero temperature. The solution is straightforward [see Carslaw and Jaeger, 1959]:

$$
T=T_{m} \text { erf }\left[z / 2(k t)^{1 / 2}\right]
$$

Typical oceanic values for $T_{m}$ and $k$ are $1200^{\circ} \mathrm{C}$ and 0.007 , respectively [Parker and Oldenburg, 1973]. The effect of including the full value of latent heat (i.e., assuming solidification

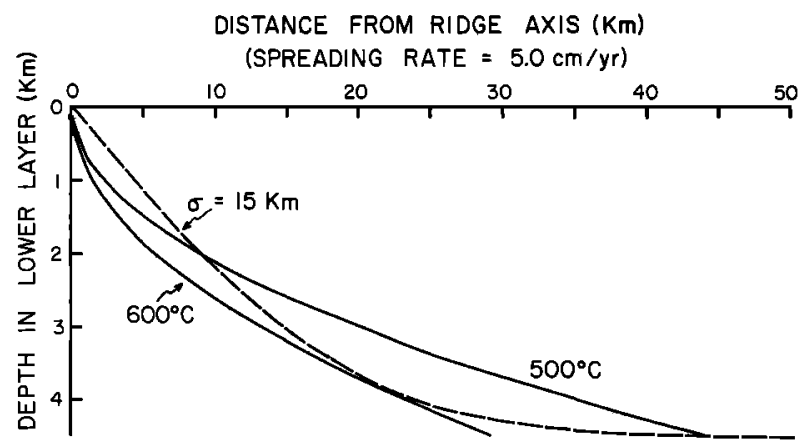

Fig. 5. Solid curves are selected theoretical isotherms calculated for a semi-infinite conducting solid, taken to be representative of the lower layer. Initial and boundary conditions are given in the appendix. Inclusion of full latent heat would increase the temperature of these isotherms by about $25 \%$. The dashed curve is the integrated halfGaussian curve $(\sigma=15 \mathrm{~km})$ for a layer thickness of $4.5 \mathrm{~km}$ that best approximates the shape of the isotherms of interest shown here. 
from a $100 \%$ melt) is to raise the temperature of a particular isotherm by $25 \%$. If the crust is formed from a partial melt, the effect would be less. The pertinent isotherms in this study (Figure 5) are those associated with the range of blocking temperatures for acquisition of thermoremanent magnetization for lower layer rocks, assumed to be between roughly $500^{\circ}$ and $600^{\circ} \mathrm{C}$.

Although the isotherms in Figure 5 are calculated for a very simple model, they closely resemble isotherms calculated by Parker and Oldenburg [1973] and Sleep [1975] for more complicated models of moderate spreading rate $(\sim 5 \mathrm{~cm} / \mathrm{yr})$ ridges. The main difference is within 2 or $3 \mathrm{~km}$ of the ridge crest, where the more complicated models assume a finite depth of intrusion. The discrepancy is only over a small portion of the total width of the transition zone.

The half-Gaussian filter is used to simulate the effect of sloping boundaries in the lower layer. The 'equivalent' halfGaussian filter refers to the integrated half-Gaussian curve, described by its standard deviation $\sigma$, which most closely approximates the shape of a sloping boundary due to isotherms (Figure 5). For a given lower layer thickness, increasing (decreasing) values of $\sigma$ for the half-Gaussian filter would correspond to decreasing (increasing) temperatures or isotherms in the layer, whereas a given value of $\sigma$ would correspond to increasing (decreasing) temperatures of isotherms in a thicker (thinner) lower layer.

It is evident from the example shown in Figure 5 that the equivalent half-Gaussian curve only roughly approximates the shape of any isotherms. However, because of the uncertainties in our knowledge of the exact thermal structure of the oceanic crust, we feel that a simple representation of sloping magnetic boundaries using the half-Gaussian filter in these initial modeling experiments is justified. More exact representations of some other crustal isotherm models could be tried, but we would expect these to produce similar phase-shifting effects.

Acknowledgments. We wish to thank R. N. Anderson, E. M. Herron, R. L. Larson, and N. D. Opdyke for critically reviewing the manuscript. Discussions with J. L. LaBrecque, M. G. Langseth, K. McCamy, and W. C. Pitman III also were very helpful. Support for this work was provided by contract N00014-75-C-0210 from the Office of Naval Research and grant DES 74-17965 from the National Science Foundation. Lamont-Doherty Geological Observatory contribution 2338.

\section{REFERENCES}

Anderson, R. N., and M. A. Hobart, The relation between heat flow, sediment thickness, and age in the eastern Pacific, J. Geophys. Res., 81(17), 1976

Anderson, R. N., S. Uyeda, and A. Miyashiro, Geophysical and geochemical constraints at converging plate boundaries, 1 , Dehy dration in the downgoing slab, Geophys. J. Roy. Astron. Soc., 44, $333-357,1976$

Atwater, T., and J. D. Mudie, Detailed near-bottom study of the Gorda rise, J. Geophys. Res., 78, 8665-8686, 1973.

Blakely, R. J., Geomagnetic reversals and crustal spreading rates during the Miocene, J. Geophys. Res., 79, 2979-2985, 1974.

Blakely, R. J., An age dependent, two-layer model for marine magnetic anomalies, in The Geophysics of the Pacific Ocean Basin and Its Margin, Geophys. Monogr. Ser., vol. 19, edited by G. H. Sutton, M. H. Manghnani, and R. Moberly, AGU, Washington, D. C., in press, 1976

Bonatti, E., J. Honnorez, P. Kirst, and F. Radicati, Metagabbros from the mid-Atlantic ridge at $06^{\circ} \mathrm{N}$ : Contact-hydrothermal-dynamic metamorphism beneath the axial valley, J. Geol., 83, 61-78, 1975.

Butler, R. F., and S. K. Banerjee, Magnetic properties of exposed oceanic crust on Macquarie Island, Nature, 244, 115-118, 1973.

Cande, S. C., A paleomagnetic pole from Late Cretaceous marine magnetic anomalies in the Pacific, Geophys. J. Roy. Astron. Soc., 44, 547-566, 1976.

Cande, S. C., and J. L. LaBrecque, Behavior of the earth's paleomagnetic field from small scale marine magnetic anomalies, Nature, 247. 26-28, 1974.

Carslaw, H. S., and J. C. Jaeger, Conduction of Heat in Solids, 510 pp., Oxford University Press, New York, 1959.

Christensen, N. I., The abundance of serpentinites in the oceanic crust, J. Geol., 80, 709-719, 1972.

Christensen, N. I., and M. H. Salisbury, Structure and constitution of the lower oceanic crust, Rev. Geophys. Space Phys., 13, 57-86, 1975.

Cox, A., R. J. Blakely, and J. D. Phillips, A two-layer model for marine magnetic anomalies (abstract), Eos Trans. AGU, 53, 974, 1972.

Fox, P. J., and N. D. Opdyke, Geology of the oceanic crust: Magnetic properties of oceanic rocks, J. Geophys. Res., 78, 5139-5154, 1973.

Fox, P. J., E. Schreiber, and J. J. Peterson, The geology of the oceanic crust: Compressional wave velocities of oceanic rocks, J. Geophys. Res., 78, 5155-5172, 1973.

Irving, E., The mid-Atlantic ridge at $45^{\circ} \mathrm{N}, 14$, Oxidation and magnetic properties of basalt; Review and discussion, Can. J. Earth Sci., 7. 1528-1538, 1970.

Larson, R. L., and C. G. Chase, Late Mesozoic evolution of the western Pacific, Geol. Soc. Amer. Bull., 83, 3627-3644, 1972.

Larson, R. L., S. C. Cande, and J. L. LaBrecque, On the permanency of magnetic anomalies, paper presented at 16 th General Assembly, Int. Union of Geod. and Geophys., Grenoble, France, 1975.

Lister, C. R. B., On the thermal balance of a mid-ocean ridge, Geophys. J. Roy. Astron. Soc., 26, 515-535, 1972.

Lowrie, W., Oceanic basalt magnetic properties and the Vine and Matthews hypothesis, J. Geophys., 40. 513-536, 1974.

Marshall, M., and A. Cox, Magnetic changes in pillow basalt due to sea floor weathering, J. Geophys. Res., 77, 6459-6469, 1972.

Miyashiro, A., F. Shido, and M. Ewing, Metamorphism in the midAtlantic ridge near $24^{\circ}$ and $30^{\circ} \mathrm{N}$, Phil. Trans. Roy. Soc. London, Ser. $A, 268,589-603,1971$.

Moores, E. M., and F. J. Vine, The Troodos massif, Cyprus and other ophiolites as oceanic crust: Evaluation and implications, Phil. Trans. Roy. Soc. London, Ser. A, 268, 443-466, 1971 .

Parker, R. L., and D. W. Oldenburg, Thermal model of ocean ridges, Nature, 242, 137-139, 1973.

Peterson, J. J., P. J. Fox, and E. Schreiber, Newfoundland ophiolites and the geology of the oceanic layer, Nature, 247, 194-196, 1974.

Schouten, H., and K. McCamy, Filtering marine magnetic anomalies, J. Geophys. Res., 77, 7089-7099, 1972.

Sleep, N. H., Formation of oceanic crust: Some thermal constraints, $J$. Geophys. Res., 80, 4037-4042, 1975.

Talwani, M., C. C. Windisch, and M. G. Langseth, Jr., Reykjanes ridge crest: A detailed geophysical study, J. Geophys. Res., 76, 473-517, 1971

Vine, F. J., and E. M. Moores, A model for the gross structure, petrology, and magnetic properties of oceanic crust, Geol. Soc. Amer. Mem., 132. 195-205, 1972.

Weissel, J. K., and D. E. Hayes, Magnetic anomalies in the southeast Indian Ocean, in Antarctic Oceanology II: The Australian-New Zealand Sector, Antarctic Res. Ser., vol. 19, edited by D. E. Hayes, AGU, Washington, D. C., 1972.

Williams, D. L., R. P. Von Herzen, J. G. Sclater, and R. N. Anderson, The Galapagos spreading center: Lithospheric cooling and hydrothermal circulation, Geophys. J. Roy. Astron. Soc., 38, 587-608, 1974.

(Received December 12, 1975; revised February 12, 1976; accepted February 25, 1976.) 